\title{
National Ignition Facility \\ Construction Safety \\ Management Review
}

Bruce E. Warner

Chairperson, Management Review Team

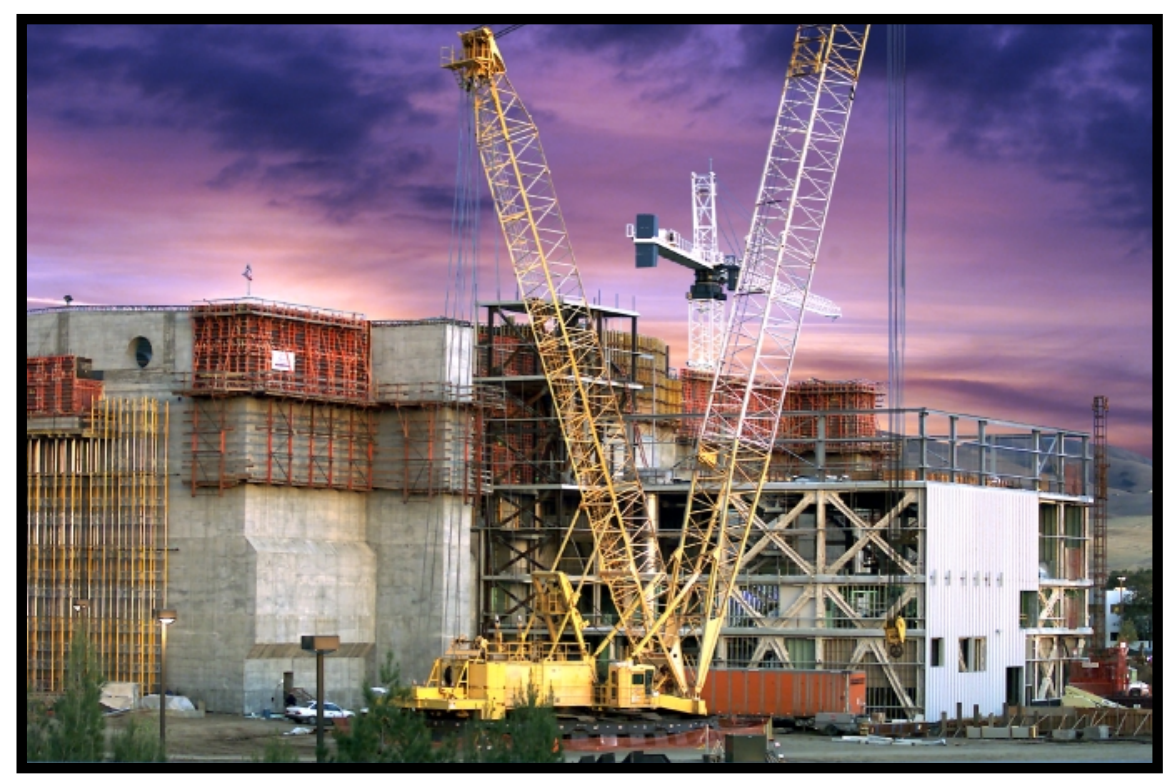

February 2000

Lawrence Livermore National Laboratory

7000 East Avenue

Livermore, CA 94550 
This document was prepared as an account of work sponsored by an agency of the United States Government. Neither the United States Government nor the University of California nor any of their employees, makes any warranty, express or implied, or assumes any legal liability or responsibility for the accuracy, completeness, or usefulness of any information, apparatus, product, or process disclosed, or represents that its use would not infringe privately owned rights. Reference herein to any specific commercial products, process, or service by trade name, trademark, manufacturer, or otherwise, does not necessarily constitute or imply its endorsement, recommendation, or favoring by the United States Government or the University of California. The views and opinions of authors expressed herein do not necessarily state or reflect those of the United States Government or the University of California, and shall not be used for advertising or product endorsement purposes.

This report has been reproduced directly from the best available copy.

Available to DOE and DOE contractors from the Office of Scientific and Technical Information

P.O. Box 62, Oak Ridge, TN 37831

Prices available from (615) 576-8401, FTS 626-8401

Available to the public from the National Technical Information Service

U.S. Department of Commerce 5285 Port Royal Rd., Springfield, VA 22161

This work performed under the auspices of the U.S. Department of Energy University of California by Lawrence Livermore National Laboratory under Contract No. W-7405-Eng-48. 


\section{NATIONAL IGNITION FACILITY}

\section{CONSTRUCTION SAfETy MANAGEMENT REVIEW}

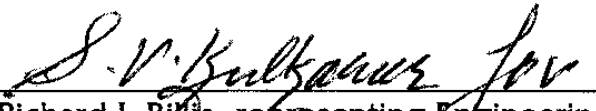

Richard J. Biffa, representing Engineering

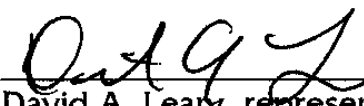

David A. Leary, representing Business Services and Public Affairs

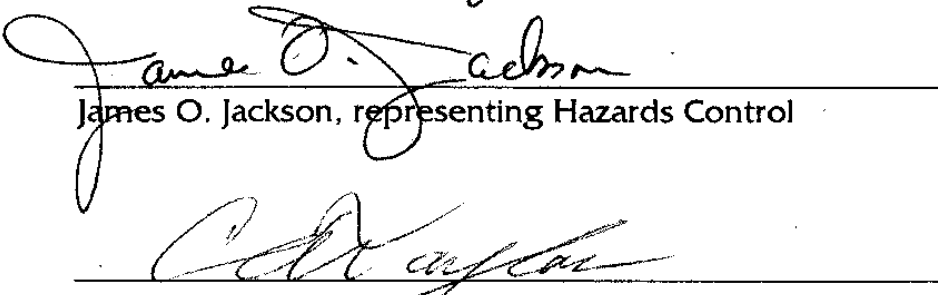

Charles A. Taylor, representing DOE OAK

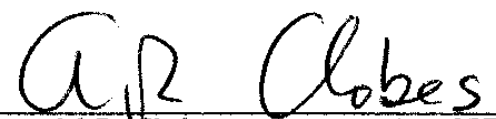

Arnold R. Clobes, representing ICF/NIF Program

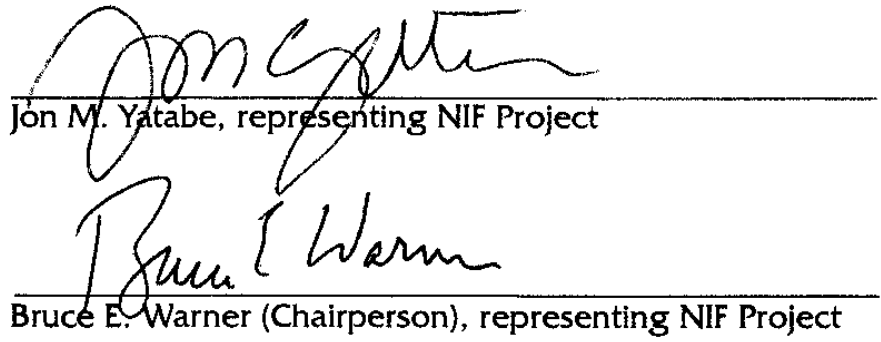




\section{CONTENTS}

Executive Summary $\ldots \ldots \ldots \ldots \ldots \ldots \ldots \ldots \ldots \ldots$

1 Introduction. . . . . . . . . . . . . . . . . 1

2 Process. .......................... 1

2.1 Phase 1 - Review Documents. ................. 2

2.2 Phase 2 - Line Management Interviews . . . . . . . . . . . . 2

2.3 Phase 3 - Managing Future Contracts for Safety . . . . . . . . . . 3

2.4 Phase 4 - The Report .................... 3

3 Review of Construction Management . . . . . . . . . . . . 3

3.1 Construction Line Management Conventional Facility Construction ............... 3

3.2 Construction Line Management Proposed Beampath Infrastructure System Installation . . . . . . . 6

3.3 Support Functions to Line Management . . . . . . . . . . . . . . 6

3.4 Summary of Observations . . . . . . . . . . . . 7

4 Recommendations . . . . . . . . . . . . . . . . . 8

4.1 Recommendations for Conventional

Facility Construction . . . . . . . . . . . . . . . . . 8

4.2 Recommendations for Future Contracts $\ldots \ldots \ldots \ldots \ldots$ 


\section{EXECUTIVE SUMMARY}

The Management Review Team reviewed eight safety documents pertaining to the NIF construction safety program and interviewed eight line managers and safety support personnel over a three-week period. This report describes the Team's observations and resultant recommendations.

The Team observed four significant safety management items:

1. The role of the Construction Manager (CM) as described in the $\mathrm{CM}$ contract language is inconsistent with the Construction Safety Program (CSP), a key governing document.

2. Proper $\mathrm{CM}$ authority for safety management has been eroded for a number of reasons, including line-management changes in roles and responsiblities without adequate review and discussion, as well as the intermingling of LLNL and CM safety personnel into $\mathrm{CM}$ responsibilities.

3. The CSP has been determined upon review to be a valuable governing document for NIF construction safety. This document was changed and updated in July 1999. Current contractors on site are working to different versions of the CSP.

4. Recent process improvements, such as the STOP work program and the Safe Plan of Action program, have not been thoroughly reviewed and incorporated into the CSP documentation.

As a result of these observations and the planned transition on the NIF site from conventional facilities construction to Beampath infrastructure systems (BIS) construction and installation, the Team arrived at a number of recommendations for both the balance of the conventional facilities construction and the upcoming BIS construction contract. These recommendations are summarized here:

\section{Recommendations for Conventional Facility Construction}

1. LLNL and the CM should work together and promptly clarify roles and responsibilities and enforce the requirements of the NIF CSP.

2. Line-management responsibilities and authorities for safety should be documented consistently throughout the Project.

3. All current and future contractors should receive and follow the July, 1999 version of the CSP (and updates as they are issued).

4. LLNL should bring in commercial expertise in construction safety management to review the current program and make recommendations for the future. 


\section{Recommendations for Future Contracts}

1. The upcoming BIS contract affords an opportunity to clarify and strengthen the NIF construction safety program implementation. LLNL should carefully consider the recommendations from an independent safety contractor.

2. The upcoming BIS contract should include a comprehensive award program that reaches down to the individual worker for safe work habits. The CM/General Contractor (CM/GC) should report quantitatively on its safety record each month.

3. The CM/GC should be fully responsible for safety with LLNL and DOE providing independent oversight and an interface to the LLNL institution.

4. All safety documents should be brought up to date and made consistent with each other and the new contract. The updated documents should be distributed to all participants.

The Team asserts that these recommendations, when implemented, will strengthen the management and execution of the NIF construction safety plan. 


\section{Introduction}

An accident occurred at the NIF construction site on January 13 , 2000 , in which a worker sustained a serious injury when a 42-inchdiameter duct fell during installation. Following the accident, NIF Project Management chartered two review teams: (1) an Incident Analysis Team to independently assess the direct and root causes of the accident, and (2) a Management Review Team to review the roles and responsibilities of the line, support, and construction management organizations involved. This report provides a discussion of the information gathered by the Management Review Team and provides a list of observations and recommendations based on an analysis of the information.

The Management Review Team includes senior managers who represent several Directorates within LLNL and DOE OAK: Dick Billia representing Engineering; Dave Leary representing Business Services and Public Affairs; Jim Jackson representing Hazards Control; Chuck Taylor representing DOE OAK; Arnie Clobes representing the ICF/NIF Program; and Jon Yatabe and Bruce Warner (Chairperson) representing the NIF Project.

The attached letter from the NIF Project Manager, Ed Moses, to the Management Review Team contains the team's Charter. The team was asked to evaluate the effectiveness of the line management and its supporting safety functions in managing safety during NIF construction. The evaluation was to include the current conventional facility construction, which is $85 \%$ complete, and upcoming activities such as Beampath Infrastructure System installation, which will begin in the next six months and which represents a significant amount of work over the next two to three years.

The remainder of this document describes the Management Review Team's review process (Section 2), its observations gathered during the review (Section 3), and its recommendations to the NIF Project Manager based on those observations (Section 4).

\section{Process}

The focus of the Management Review Team (Team hereafter) was the NIF Construction line-management structure. The review strategy was to ascertain from existing documentation and through personnel interviews what the defined roles, responsibilities, safety support, and authority are for each element of the line management. The four phases of the process are described below. 


\subsection{Phase 1 - Review Documents}

The first step in acquiring the necessary information was to provide each Team member with the following documents for review:

1. Construction Safety Program for the National Ignition Facility, UCRL-ID-125990 Rev. 2.

2. Construction Safety Program for the National Ignition Facility Appendix A, UCRL-ID-125990 Rev.1.

3. Construction Safety Program for the National Ignition Facility, Appendix B, UCRL-ID-125990 Rev.1.

4. Scope of Work for Construction Management Services, Laser and Target Area Building and Optics Assembly Building for the National Ignition Facility, NIF-0001659 Rev. 2.

5. Sverdrup Facilities Inc., Subcontract \#B265202.

6. NIFCO Organization Chart, PO1432-eim-u-006.

7. Memo - Revisions to the NIF Construction Safety Program, NIF-0039060.

8. Memo - Recommendations for NIF Site Activities, NIF-0040550.

The foundation of the safety program is Reference 3 of this document, the Construction Safety Plan for the National Ignition Facility (CSP), July 1999. The CSP describes roles and responsibilities and a consistent set of safety requirements.

\subsection{Phase 2 - Line Management Interviews}

After reviewing the written expectations for the line-management structure, the Team elected to interview key personnel from each element of the NIF construction management chain to determine how the system really works (i.e., in practice rather than in theory). The interviews started with the LLNL Site Manager and proceeded down the management chain to the subcontractor level. The following individuals were interviewed:

1. LLNL Site Manager.

2. LLNL Beampath Infrastructure System (BIS) Associate Project Manager.

3. Construction Manager (CM) Field Construction Manager.

4. CM Quality Manager for Construction.

5. LLNL Safety Coordinator.

6. CM Safety Officer.

7. Construction Contractor Project Manager.

8. Construction Subcontractor Supervisor. 


\subsection{Phase 3 - Managing Future Contracts for Safety}

The Team was concerned that the present Construction Management Services contract had conflicting expectations for the CM contractor and was concerned that this could carry over to future contracts. To investigate that concern, the Team reinterviewed the BIS Associate Project Manager to determine what changes, if any, were being planned into future contract language that might clarify the roles and responsibilities for each element of the management chain.

\subsection{Phase 4 - The Report}

At the conclusion of the interviews, all members of the Team provided input, and a draft report was prepared for review and comment. After numerous iterations, the Team reconvened for a final review. The final report (i.e., this document), which includes recommendations to the NIF Project Manager, was signed by all Team members.

\section{Review of Construction Management}

This section provides the team's review of the construction linemanagement and support functions involved in the control of safety at the NIF site. The review was based on the interviews and document reviews described in Section 2, "Process."

This section divides the review into subsections addressing construction line management for Conventional Facilities (Section 3.1) and upcoming contracts (Section 3.2), support functions to line management (Section 3.3), and a summary of the Team's observations (Section 3.4).

\subsection{Construction Line Management - Conventional Facility Construction}

The line-management structure for the NIF Project is documented in several management and contractual documents. Roles and responsibilities can be found in the Project Execution Plan, ES\&H Management Plan, CSP, Construction Manager Contract, and the Construction Subcontractor Packages. The documents are of various dates of issue. The Project Execution Plan and ES\&H Management Plan have not been updated since 1997, while the CSP was updated in July 1999.

An updated organization chart was issued in November 1999. The new roles for special equipment, activation, and refurbishment described by this organization chart are not completely reflected in the CSP. Conventional Facility construction is now 85\% complete. The line-management responsibilities for facility construction are 


\subsubsection{LLNL}

\subsubsection{Construction Manager}

appropriately stated in the CSP (however, there are some changes in title descriptions). The NIF Project Manager has assigned ES\&H line responsibility, through the LLNL Site Manager, to the LLNL BIS Associate Project Manager down to the CM. Authority flowdown continues from the $\mathrm{CM}$ to the construction contractors and from the construction contractors to their construction subcontractors (subcontractors have contracts directly with the construction contractors). The CM is responsible for providing the necessary ES\&H resources to assure safe operations at the site.

The three subsections below focus on the three pertinent levels of line management: LLNL, the construction manager, and contractors and subcontractors.

The Team interviewed two key LLNL line managers. The LLNL Site Manager is the line manager with overall responsibility for implementing construction safety at the site. When this review began, the Site Manager also served as the Deputy Assembly and Installation Manager. Shortly thereafter the NIF Project Manager reassigned all other duties so that the Site Manager could completely focus on site management and assuring safe work performance.

The second manager in the chain, the BIS Associate Project Manager, is responsible for management of the CM contract and is responsible for both the execution of the conventional facilities construction and the planning (and eventually) the construction of the BIS. This individual is line responsible for safety on the site, but has many other responsibilities.

Both the LLNL Site Manager and the BIS Associate Project Manager stated that the $\mathrm{CM}$ is the line manager responsible for interacting with the construction contractors and subcontractors to assure safety. They also indicated that the $\mathrm{CM}$ implementation did not always meet their expectations. Note that the Team is not aware of any letters or other formal correspondence from LLNL to the CM expressing concern that the $\mathrm{CM}$ was not exercising its expected authority over safety. The next section describes this further.

The $\mathrm{CM}$ line managers interviewed stated that the current linemanagement roles and responsibilities are adequately defined in the CSP, as are those of the other organizations. (The CM is the indicated line manager directing the construction contractors and subcontractors.) The CM and LLNL safety officers did not support this statement, however, stating that they were not sure the $\mathrm{CM}$ had line-management responsibility for safety. The Team supports the observations of the safety officers; the $\mathrm{CM}$ contract as implemented does not support the line-management role stated in the CSP. In the assignment of functions, the CM is listed in its contract with LLNL as participating 
and providing assistance to LLNL, rather than being responsible for carrying out the line-management role.

A significant finding of the team is that the $\mathrm{CM}$ has operated tentatively and appears unsure of both its appropriate role and the extent of its authority to direct the construction contractors and subcontractors. The CM's tentativeness to act appears to have increased when issues have arisen and LLNL management has interceded (e.g., work suspension and safety reviews by LLNL management following an accident). LLNL's actions appear to undermine the authority of the CM with the construction contractors and their subcontractors. Note also that LLNL holds the contracts with the construction contractors, which contributes to the erosion of the CM's authority.

The role of the $\mathrm{CM}$ as the line manager responsible for site safety is unclear both in contracting and in practice, allowing the CSP to be carried out differently than intended. The interactions with the contractors do not always occur through the $\mathrm{CM}$, so multiple chains of responsibility exist. LLNL and DOE appear to have fallen into the trap of commingling their efforts with those of the CM, thus interfering with it and confusing lines of responsibility. In addition, it appears that the $\mathrm{CM}$ has been reluctant to ensure it has a proper resource level in order to effectively carry out its safety role.

The present CM also appears to lack sufficient Integrated Safety Management (ISM) training; during interviews the line manager's responses indicated limited knowledge of ISM.

\subsubsection{Construction Contractors and Sub- contractors}

The construction contractor and subcontractor Line Management was not certain of the CM's line-management authority versus that of LLNL's line management. One concern expressed by the subcontractor was that the construction contractor and the $\mathrm{CM}$ were not always effective in resolving intercontractor safety issues (e.g., one subcontractor created hazards by working above another subcontractor). The Team observed that the construction contractor acknowledged its line responsibility to ensure safety of the subcontractors but did not always effectively implement a comprehensive safety program with the subcontractors.

For the Conventional Facility construction, there are also issues that affect safety in contract administration of award fee. The construction contractor stated that its award fee was weighted 5 to 1 of cost/ schedule over safety. The construction contractor interviewed took a punitive view of the awarded fee, stating that if they lost the fee for safety performance, the subcontractor that had the accident would pay by losing his fee. This acrimony over award fee and the use of safety performance as a penalty rather than an incentive was observed during interviews by the Team. 


\subsection{Construction Line Management - Proposed Beampath Infrastructure System Installation}

The next phase of the NIF deployment is to begin later in this year. It involves installing the structures, utilities, vessels, and beam tubes that are needed to hold the laser system. Current plans expressed by the BIS Associate Project Manager indicate that a major industrial contract will be utilized to carry out this activity. This undertaking is of the same order of magnitude as the conventional facility construction, with compounded safety risks because more diverse work activities will occur simultaneously in the same area during this phase.

With new Construction Subcontract Packages coming on line in the near future, it is imperative that the organization structure, roles, and responsibilities are clearly defined. This is especially true because the proposed method of accomplishment, which is scheduled to be approved by the DOE, is for the Construction Manager/General Contractor (CM/GC) to contract or self-perform all of the work and to have overall line-responsibility for cost, schedule, and safety at the site. LLNL will have the right to approve the selected subcontractors. This Team understood that the $\mathrm{CM}$ / GC will establish and enforce the safety process for LLNL and contractor personnel working on the site within the CM/GC's work areas. This Team observed that a two-tier safety program that treats LLNL personnel differently than the contractors in terms of safety will not work effectively.

Metrics and safety expectations (e.g., award-fee criteria) for the safety performance were discussed during the interviews. The Team found this and self-assessment to be areas requiring attention (as noted in Section 4, "Recommendations").

\subsection{Support Functions to Line Management}

The safety support functions include the LLNL, CM, and construction contractor safety officers (subcontractors are not required to have full-time safety officers). It also includes the Insurance Agency and Insurers Agent's safety officers. Other support comes from environmental analysts, quality assurance and quality control inspectors, biologists, etc. They provide support in the form of expert review, observation, and consultation for the line management.

The support function of chief interest in the Team's review was that of the safety officers. Their role is defined in the CSP, and they generally follow the CSP's definitions. The CM was unable to provide the required ES\&H support staff; this has caused LLNL to supply ES\&H support personnel. (It is not clear to the Team why the $\mathrm{CM}$ was unable to provide the required support.) This action made the safety support organization confusing: LLNL personnel report directly to the $\mathrm{CM}$ in some cases and in other areas report 
to the Beampath Infrastructure Associate Project Manager or the Project Assurances Manager.

The construction contractor stated that he was confused about whom the safety officers reported to and what their authority was with regard to its workers. The safety officers themselves state that communications did not flow well and that information often did not get to the subcontractors and the workers. The construction contractor provided the safety officer for the subcontractors, who have periodic visits from their own safety officers but do not have full-time safety officers of their own. The accident record of the subcontractors shows that there is a problem, potentially worsened by the lack of dedicated safety presence at the lowest level of the work. The safety officers pointed out that they have other tasks such as paperwork and accident reporting systems that take them out of the field. In spite of these shortfalls, the safety officers consistently understood the site safety rules and generally worked together.

\subsection{Summary of Observations}

In summary, the Team had four key observations, which are described below. Recommendations based on these observations are described in Section 4.0, "Recommendations."

Role of the CM. The Team read the CM's contract language and noted that the CM's role in the safety program could be interpreted as advisory. This conflicts with the intent of the CSP, in which the CM is expected to play a strong line-management role. The Team's interviews with LLNL management revealed that the CM has not performed at the level anticipated by the CSP, nor is the LLNL management confident under the current contract and management that the CM could manage the construction site safety program without significant assistance. Despite these concerns, the Team was not shown any letters or other formal correspondence from LLNL expressing concern that the $\mathrm{CM}$ was not exercising its expected authority over safety.

CM Authority. LLNL management has at times done the work of the $\mathrm{CM}$, eroding the CM's authority with the construction contractors. LLNL has also provided safety personnel to work under the CM when the $\mathrm{CM}$ was unable to promptly hire safety officers. This intermingling of LLNL personnel with contractor personnel has caused confusion for both the safety personnel and the contractors.

Construction Safety Program Review. The CSP is the governing safety document. It was reviewed by the DOE Safety Management Evaluation Team and received high marks, and DOE OAK does quarterly safety reviews. The CSP was updated in July 1999, however. 
The update incorporates the new line-management responsibilities, new requirements form the updated LLNL ES\&H Manual, and the DOE/LLNL integrated safety management system. The updated CSP was reviewed with all construction contractors before issue. The Team has reviewed the CSP and found it to be a solid foundation for an effective safety program. The line-management decision at that time (July 1999) was to send the updated CSP to new construction contractors only and allow existing contractors to use the earlier version issued with the contracts.

Safety Program Implementation. While the CSP provides for a solid foundation for the safety program, there is not a uniform safety implementation at the site. Specific observations of inconsistency included rules followed, safety incentives, and disciplinary actions for disobeying safety rules. The Team has noted that new safety initiatives such as the Safe Plan of Action and the STOP process are being implemented. The Team did not, however, observe integration of these new initiatives with the Construction Safety Program.

\section{Recommendations}

The Team's recommendations are made in two groups: (1) recommendations to improve the conventional facility construction safety, and (2) recommendations for future contracts, such as the BIS construction.

\subsection{Recommendations for Conventional Facility Construction}

1. In light of the fact that the $C M$ has not aggressively exerted the intention of the CSP in their role, it is critical that LLNL and the $\mathrm{CM}$ work together and promptly clarify roles and responsibilities and enforce the requirements of the NIF CSP. The CM and the contractors should perform a monthly self-assessment of safety performance against established metrics.

2. Line-management responsibilities and authorities for safety should be documented consistently throughout the Project.

3. To assure a uniform construction safety program, all current contractors should receive the July 1999 version of the NIF CSP for compliance (and updates as they are issued). LLNL and the CM should ensure execution of a uniform and consistent safety program, which treats all workers equally on the construction site, follows LLNL permitting processes, communicates and receives worker feedback, and includes worker safety incentives and disciplinary action for safety violations. 
4. LLNL should bring in commercial expertise in construction safety management to review the current construction safety program and make recommendations for future contracts, such as the BIS contracts.

\subsection{Recommendations for Future Contracts}

1. Prior to the start of the proposed BIS construction, line-management responsibilities and authorities for safety should be documented. This should be consistent with the responsibilities of the proposed CM/GC Contract to develop and enforce a comprehensive construction safety program as the responsible line manager either contracting for or self-performing its work. This safety program should apply equally to LLNL participants in the construction zones. The CM/GC Contract should incorporate DOE/LLNL ISM requirements and principles. The safety program should be reviewed by an independent safety contractor, with recommendations considered for inclusion. These safety program documents should be approved by LLNL and reviewed by DOE.

2. The proposed CM/GC contract should establish a set of awardfee goals for safety that flows down to the subcontractors. The award fee should include quantitative metrics based on recordable case rates to measure the effectiveness of the safety program. It should also include an effective safety incentive system that flows all the way down to the workers, rewarding them appropriately for excellent safety performance. Each month, the CM/GC should perform a self-assessment of safety performance.

3. The proposed CM/GC should provide all safety. LLNL should provide independent oversight of the CM/GC safety program to assure LLNL and DOE requirements are satisfied and to interface with the LLNL institution (e.g., traffic safety, security).

4. Documents that address various management roles and responsibilities (e.g., CSP, Management Plan) should be brought up to date, made consistent, and maintained on a regular basis. They should be distributed to all participants. 